\title{
Chiari type I and II malformations
}

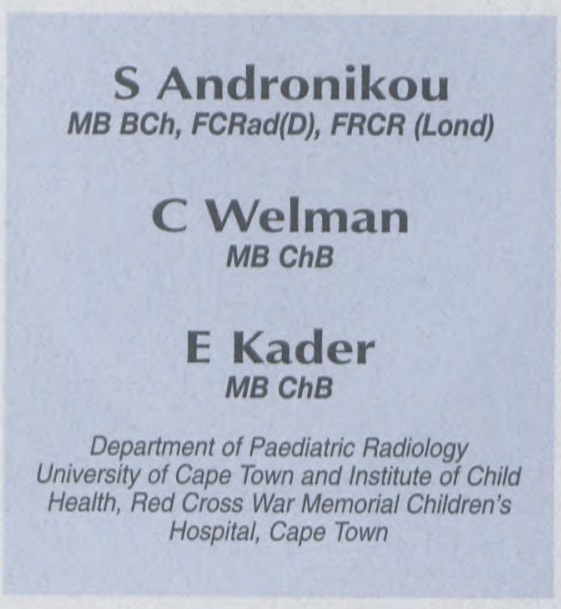

Despite the same name, Chiari types I and II are unrelated entities. Chiari II malformation is initially encountered in children, occurring in virtually all those who have myelomeningocoele.

\section{Chiari type II malformation}

This is also known as the ArnoldChiari malformation. Once a myelomeningocoele has been closed surgically after birth, most patients develop hydrocephalus. This is the commonest indication for radiological evaluation at which time the features of Chiari type II will be visualised. This anomaly is formed when the posterior neuropore fails to close resulting in failure of the ventricles to expand and so create a normal size posterior fossa with subsequent failing in separation of the thalami. ${ }^{1}$ Intra-uterine surgical closure of the m y e lo me n i n o c o e l e (http://www.fetalsurgery.com) prevents development of this malformation. The imaging features result from

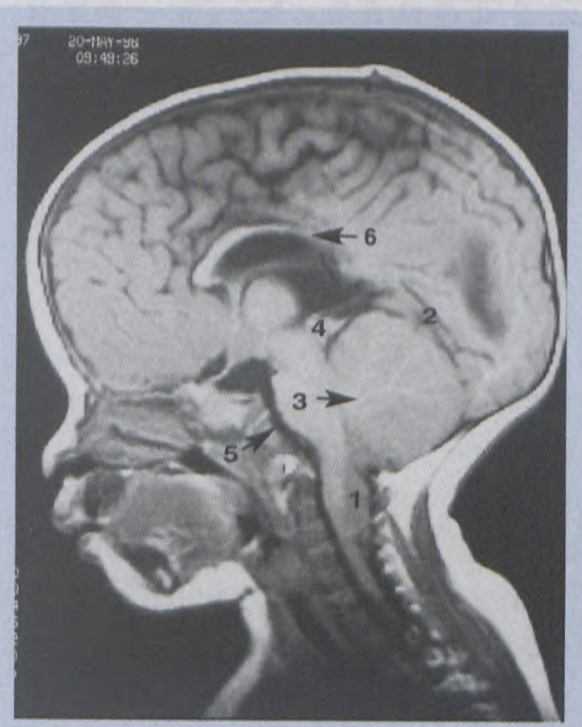

Fig. 1. Chiari type II malformation. Sagittal T1 weighted MRI image shows the small posterior fossa, tonsillar vermian herniation through foramen magnum (1), low-lying venous confluence with a steep (vertically orientated) straight sinus (2), lowlying 4th ventricle with a narrow AP diameter (3), tectal (quadrigeminal plate) beaking (4), scalloped clivus (5) and corpus callosum hypogenesis (6). Many of the supratentorial features (not shown here) are best seen on axial images.

squeezing of the growing cerebellum out of a small posterior fossa. The radiological features are best demonstrated on a sagittal $\mathrm{T} 1$ weighted MRI image.

\section{Chiari type I}

This is usually an isolated abnormality but can be seen with conditions that have a small posterior fossa. The subgroups of this entity relate to various craniocervical junction abnormalities. Caudal cerebellar tonsillar ectopia is the primary abnormality. In adults and children less than 5 years of age, projection of the cerebellar tonsils below the foramen magnum of greater than $5 \mathrm{~mm}$ is abnormal. Between the ages of 5 and 15

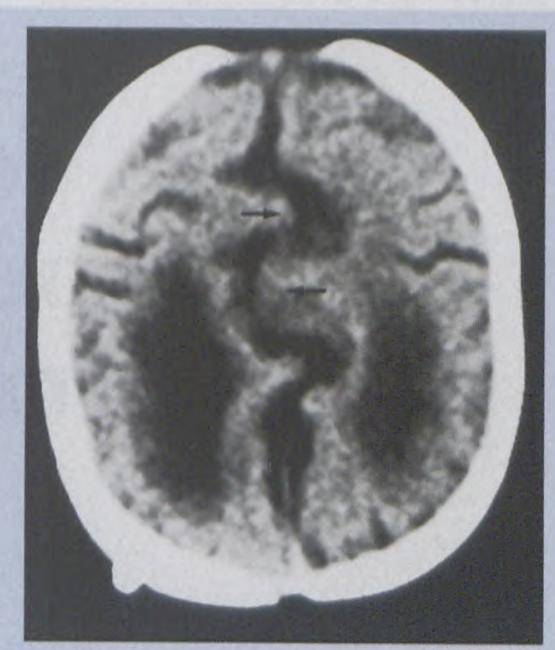

Fig. 2. Axial CT scan through the high parietal region shows marked cerebral interdigitation (arrows) through a fenestrated falx cerebri. Note the parallel lateral ventricles which are prominent posteriorly.

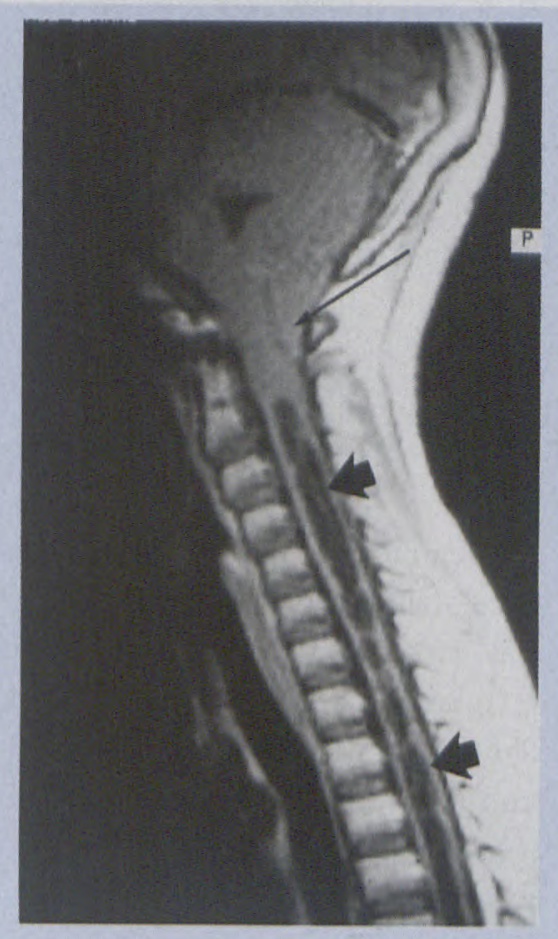

Fig. 3. Chiari type I malfomation. Sagittal T1 weighted MRI image shows the tonsillar ectopia (long arrow). Associated syringohydromyelia (short arrows) can be found in $20-25 \%$ of these patients.

years tonsillar ectopia is only pathological when there is more than $6 \mathrm{~mm}$ projecting through the foramen magnum.

\section{Reference}

1. Barkovich AJ. Paediatric Neuroimaging. 2nd ed. Philadelphia: Lippincott-Raven, 1996: 238-247, $455-488$. 